\title{
Autoaugmentation Mastopexy with an Inferior-Based Pedicle
}

\author{
Johannes Franz Hönig · Hans Peter Frey · \\ Frank Michael Hasse $\cdot$ Jens Hasselberg
}

Received: 21 June 2008 / Accepted: 22 September 2008/Published online: 19 February 2009

(c) Springer Science+Business Media, LLC and International Society of Aesthetic Plastic Surgery 2009

\begin{abstract}
Mammaplasty for breast enhancement and correction of ptosis augmentation is described. Between 2002 and 2007, autoaugmentation mammaplasty was performed for 27 patients (age, $48 \pm 7.3$ years) using an inferior-based flap of deepithelialized dermoglandular tissue inserted beneath the breast parenchyma of a superiorbased nipple-areolar complex pedicle. The results confirmed that autoaugmentation mammaplasty corrects ptosis while increasing the projection and apparent volume of the breast. The degree of inframammary fold (IMF) descent 6 months after surgery generally paralleled that of the nipple. The mean level of the IMF was below the mean level of the nipple. Postoperatively, the optimum distance had been largely achieved. The advantage of the technique is that it optimizes the shape and volume of the breast without the use of an implant.
\end{abstract}

Keywords Autoaugmentation mammaplasty ·

Breast ptosis · Mastopexy

Autoaugmentation mammaplasty is an alternative for patients with small breasts who desire improvement in their breast shape without the use of an implant [1-12]. This

J. F. Hönig · F. M. Hasse · J. Hasselberg

Paracelsus Clinic Hannover, Hannover, Germany

J. F. Hönig ( $ه)$

Department Plastic Surgery, University Hospital and Medical

School of Goettingen, Robert-Koch-Street 40, 37075 Goettingen,

Germany

e-mail: info@professor-hoenig.de

H. P. Frey

Clinic im Loewen-Center Luzern, Luzern, Switzerland procedure corrects ptosis while increasing the projection and apparent volume of the breast when mastopexy is used.

The goal of autoaugmentation mammaplasty is to give the breast volume. Using the inferior pedicle described by Ribeiro et al. [3, 4] in 1971 or the vertical pedicle described by McKissoc [9], volumetric transfer of the back of the central pedicle augments the breast projection. At followup evaluation, autoaugmentation mammaplasty is assessed, with special attention paid to the long-term results in terms of breast shape.

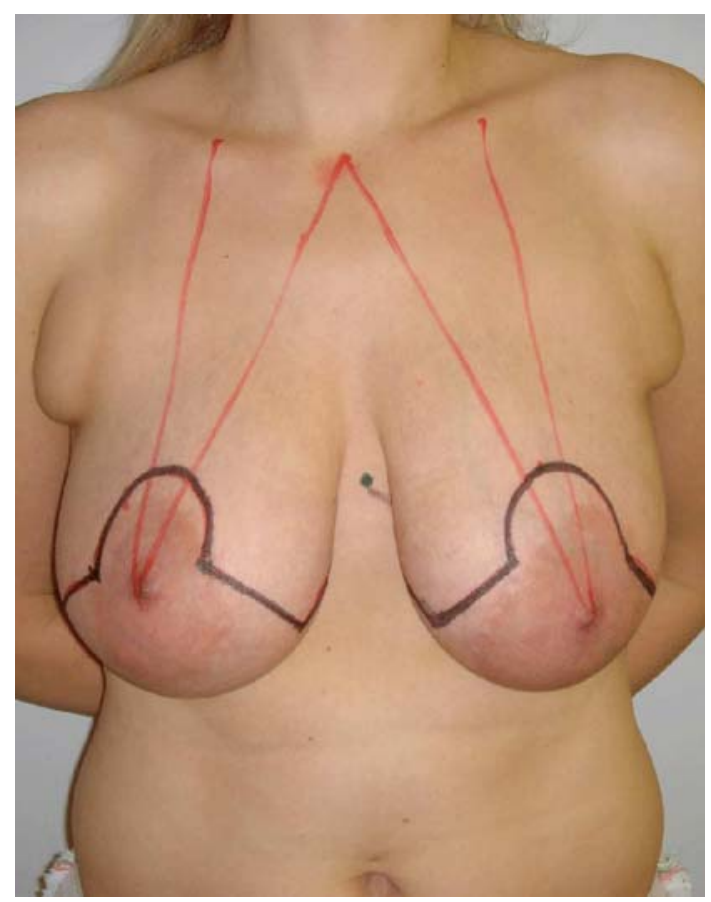

Fig. 1 Preoperative view showing the preoperative markings for a patient undergoing autoaugmentation mammaplasty 
Table 1 Pre- and postoperative evaluation of the NAC positioning $(n=27)$

\begin{tabular}{lccc}
\hline Distance & $\begin{array}{l}\text { Preoperative } \\
(\mathrm{cm})\end{array}$ & $\begin{array}{l}\text { After 6 months } \\
(\mathrm{cm})\end{array}$ & \multicolumn{1}{l}{$\begin{array}{l}\text { After } 12 \text { months } \\
(\mathrm{cm})\end{array}$} \\
\hline N-SN & $25.2 \pm 0.9$ & $20.2 \pm 0.7$ & $21.3 \pm 0.6$ \\
N-IMF & $9.3 \pm 0.8$ & $7.1 \pm 0.7$ & $7.3 \pm 0.3$ \\
IMD & $3.4 \pm 0.1$ & $2.8 \pm 0.9$ & $3.2 \pm 0.7$ \\
\hline
\end{tabular}

$N$-SN distance between the nipple and the sternal notch, $N$-IMF distance between the nipple and the inframammary fold, IMD intermammary distance
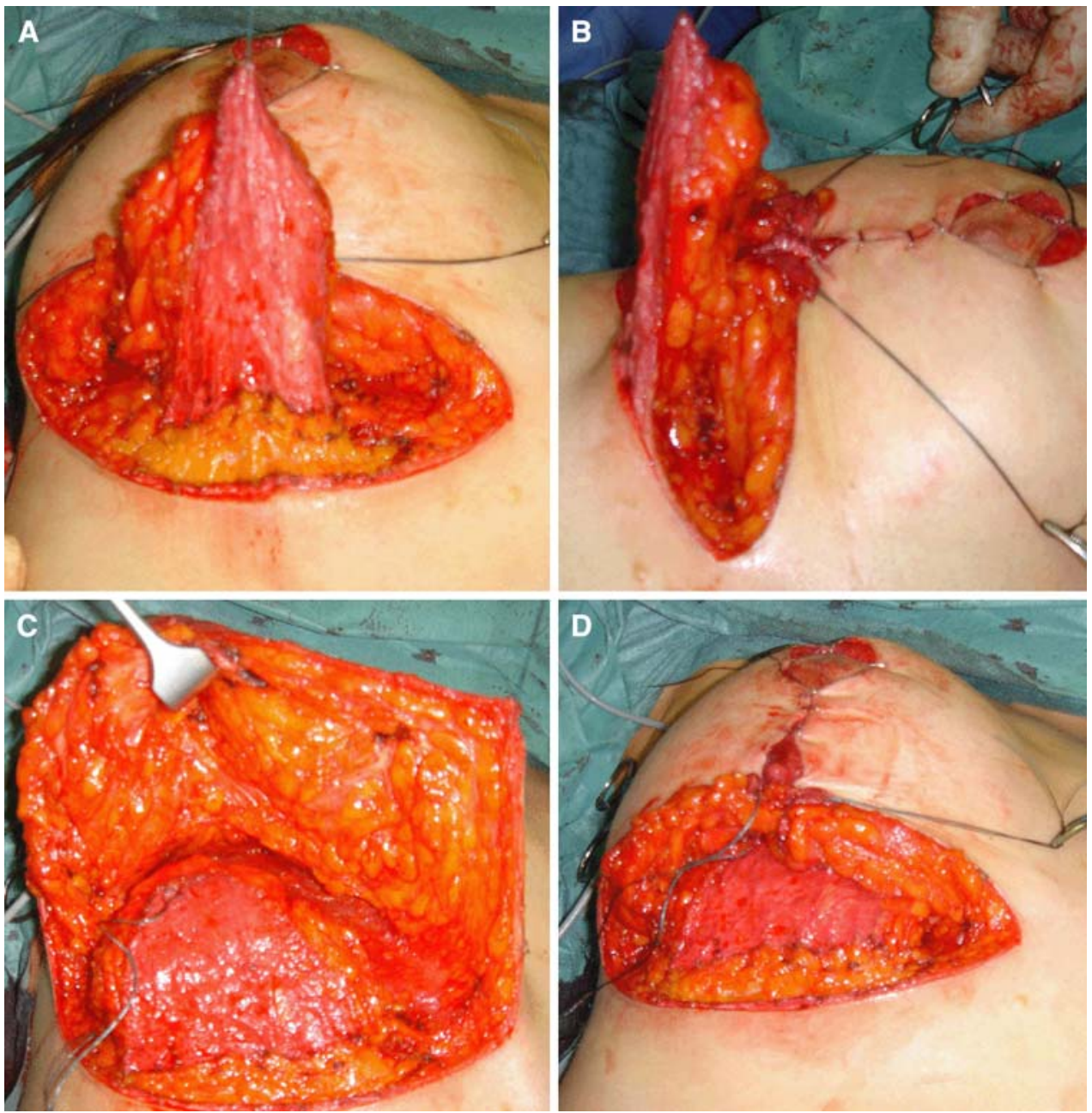

Fig. 2 a Frontal intraoperative view of a patient undergoing autoaugmentation mammaplasty using an inferior-based flap of deepithelialized skin and subcutaneous breast tissue modulated to its pedicle inserted beneath a superior pedicle to correct ptosis and to increase the projection and apparent volume of the breast. b Lateral intraoperative view of a patient undergoing autoaugmentation mammaplasty with a superior pedicle mastopexy technique using a deepithelialized inferior-based flap of subcutaneous and breast tissue as a foundation with the superior nipple-areola complex (NAC) seated over the flap

\section{Indications}

Autoaugmentation mammaplasty is suitable for patients with small or ptotic breasts who desire repositioning of their breasts but do not wish to undergo a breast implant.

\section{Patients and Methods}

Between 2002 and 2007, autoaugmentation mammaplasty was performed for 27 patients (age, $48 \pm 7.3$ years). All

on top. c Frontal intraoperative view a patient undergoing autoaugmentation mammaplasty with a superior pedicle mastopexy technique using a deepithelialized inferior-based flap. The flap has been sutured to the pectoralis major fascia. Note the volume of the modulated flap. d Oblique intraoperative view of a patient undergoing autoaugmentation mammaplasty with a superior pedicle mastopexy technique using a deepithelialized inferior-based flap. The skin has been draped 
Table 2 Pre- and postoperative evaluation of nipple (N) and inframammary fold (IMF) positioning $(n=27)^{\mathrm{a}}$

\begin{tabular}{llll}
\hline Level & Preoperative $(\mathrm{cm})$ & After 6 months $(\mathrm{cm})$ & After 12 months $(\mathrm{cm})$ \\
\hline $\mathrm{N}$ to $\mathrm{Y}$ & $4.2 \pm 3.2$ & $1.2 \pm 2.1$ & $1.4 \pm 1.8$ \\
IMF to $\mathrm{Y}$ & $5.8 \pm 2.2$ & $4.3 \pm 1.8$ & $4.8 \pm 1.7$
\end{tabular}

${ }^{a}$ Level of nipple (N) and level of the inframammary fold (IMF) to Y. Pre- and postoperative lateral views in a series of autoaugmentation mammaplasties. $\mathrm{Y}$ is the midpoint between the tip of the acromion and the lateral epicondyle minus $1 \mathrm{~cm}$

Table 3 Pre- and postoperative evaluation of nipple projection $(n=27)^{\mathrm{a}}$

\begin{tabular}{llll}
\hline Distance & Preoperative $(\mathrm{cm})$ & After 6 months $(\mathrm{cm})$ & After 12 months $(\mathrm{cm})$ \\
\hline $\mathrm{Npr}$ to $\mathrm{Ch}=\mathrm{Z}$ & $4.6 \pm 1.2$ & $5.6 \pm 1.1$ & $4.9 \pm 1.2$ \\
\hline
\end{tabular}

${ }^{a}$ Projection of the nipple (Npr) to a perpendicular line of the chest $(\mathrm{Ch})$ wall in patients standing erect in a series of autoaugmentation mammaplasties before and after surgery. $Z=$ distance from nipple to chest wall

the patients underwent a thorough, individualized preoperative evaluation to establish a correct diagnosis, exclude malignancies, and determine the level of the new nipple position.

For all the patients, the distance between the nipple and the sternal notch, the distance between the nipple and the inframammary fold, and the intermammary distance were measured preoperatively then 6 and 12 months after surgery (Fig. 1, Table 1).

\section{Surgical Techniques}

With the patient under general anesthesia, autoaugmentation mammaplasty was routinely performed. Markings were performed preoperatively with the patient in a standing position (Fig. 1). Establishment of the new nipple position was the most important step. The best way to estimate nipple position is by measuring the proposed new nipple from the fixed point of the suprasternal notch. The final nipple position was established with the patient sitting up at $90^{\circ}$ on the operating table.

The breast tissue was reconfigured to produce the best possible shape by narrowing the base dimension and position of the breast, which usually entailed central transposition of tissue. This was achieved with a superior pedicle mastopexy technique using a deepithelialized inferior-based flap of subcutaneous and breast tissue as a foundation with the superior nipple-areola complex (NAC) seated on top (Fig. 2a-d).

The inferior pedicle was drawn with a width of 5 to $6 \mathrm{~cm}$, a length $2 \mathrm{~cm}$ below the NAC, and a thickness not less than $2 \mathrm{~cm}$. After deepithelialization of the periareoalar and pedicle area, the marked flap was incised. After the parenchyma had been undermined toward the upper pole, the inferior deepithelialized pedicle was raised and both the subcutaneous tissues and the breast parenchyma of the central lower breast were folded beneath the nipple and areola to maximize upper breast volume (Fig. 2a-d). The pedicle was fixed to the pectoralis major fascia without any restriction behind the NAC (Fig. 2c).

After the flap was tacked to the chest wall with $3 \times 0$ polydioxanon sutures, closure of the medial and lateral pillars over the flap optimized upper pole fullness. Closure of the periareloar incision was performed via a round block technique using a purse-string suture as described by Hammond et al. [2].

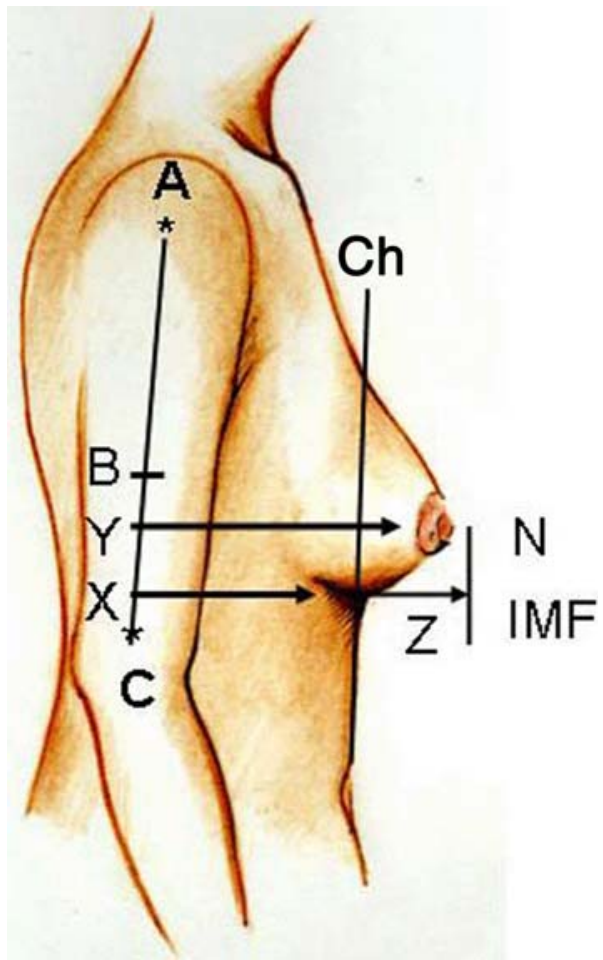

Fig. 3 Schematic drawing of the pre- and postoperative measurements of the nipple and inframammary fold (IMF) position. The level of the nipple (N) and the level of the inframammary fold (IMF) to $\mathrm{Y}$ are measured in the lateral view in a series of autoaugmentation mammaplasties pre- and postoperatively. $\mathrm{Y}$ is the midpoint (B) between the tip of the acromion and the lateral epicondyle minus $1 \mathrm{~cm}$. $\mathrm{X}$ is the level of the IMF measured to $\mathrm{Y}$ 


\section{Results}

The median follow-up period was $18 \pm 2.1$ months. Immediate healing was achieved without complications, adverse reactions, or side effects. All patients healed uneventfully without any postoperative problems. No swelling or seromatous fluid collection necessitated a second procedure or a prolonged drainage. No partial or total necrosis of the nipple or hypertrophic scarring was detected.

The surgical outcome was evaluated according to analyses performed before and after surgery based on pre- and postoperative measurements (Fig. 3). The aesthetic results were considered good to excellent in all cases, and the contour results were stable in the long-term follow-up evaluation (Figs. 4 and 5).
The degree of inframammary fold (IMF) descent 6 months postoperatively generally paralleled that of the nipple (Tables 1 and 2). The mean level of the inframammary fold was below the mean level of the nipple. Postoperatively, the optimum distance had been largely achieved. There was a descent of the inframammary fold and that of the nipple projection as a result of whole breast ptosis (Table 3).

\section{Discussion}

Autoaugmentation mammaplasty dates back to Ribeiro's [3, 4] report in 1971. This procedure removes breast tissue from the area with more tissue and places it in an area with
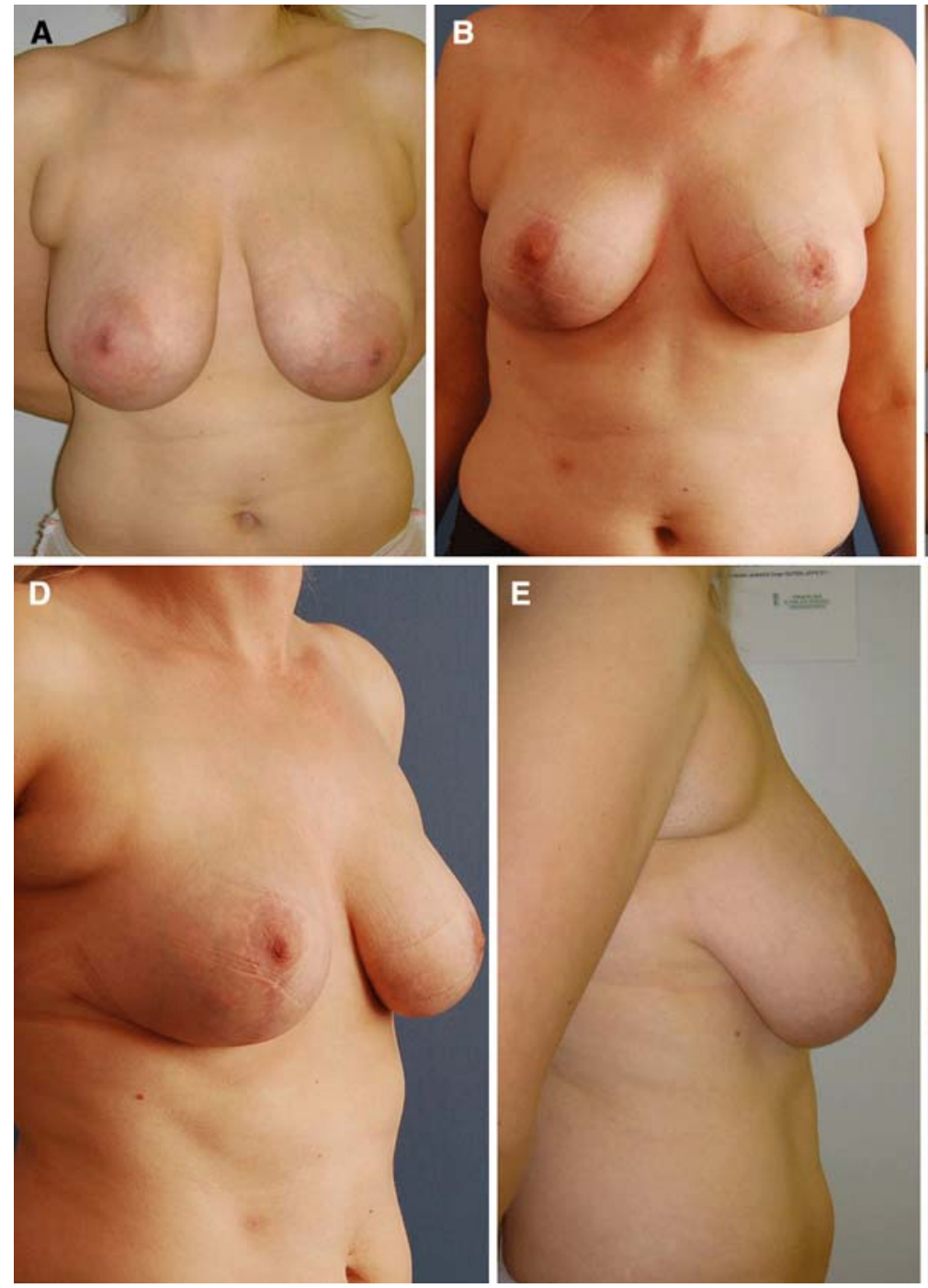
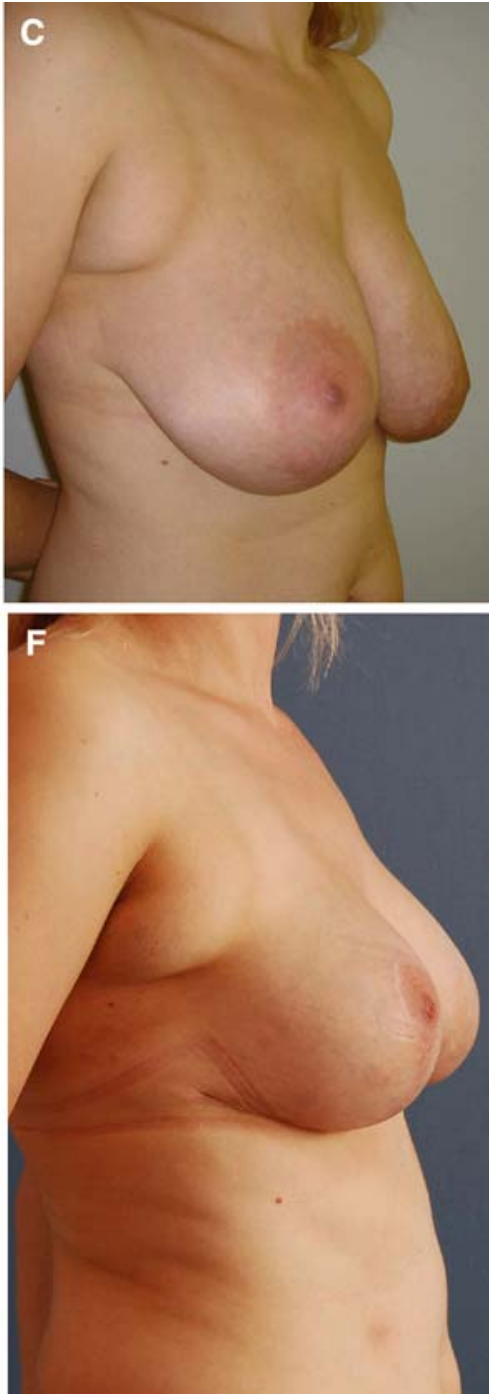

Fig. 4 a Preoperative frontal view of a patient undergoing autoaugmentation mammaplasty using an inferior-based deepithelialized flap in combination with a vertical mastopexy technique for breast enhancement. b Postoperative frontal view 12 months after surgery. c Preoperative right oblique view. d Postoperative right oblique view. Note the projection of the nipple-areola complex (NAC). e Preoperative lateral view. f Later view 12 months after surgery 
Fig. 5 a Preoperative frontal view of a patient undergoing autoaugmentation

mammaplasty using an inferiorbased deepithelialized flap in combination with a vertical Lejour reduction/mastopexy technique. b Postoperative frontal view 12 months after surgery. c Preoperative left oblique view. Note the ptosis and flatness of the breast. d Postoperative oblique view after autoaugmentation mammaplasty. The nippleareola complex (NAC) has an improved projection without the use of an implant
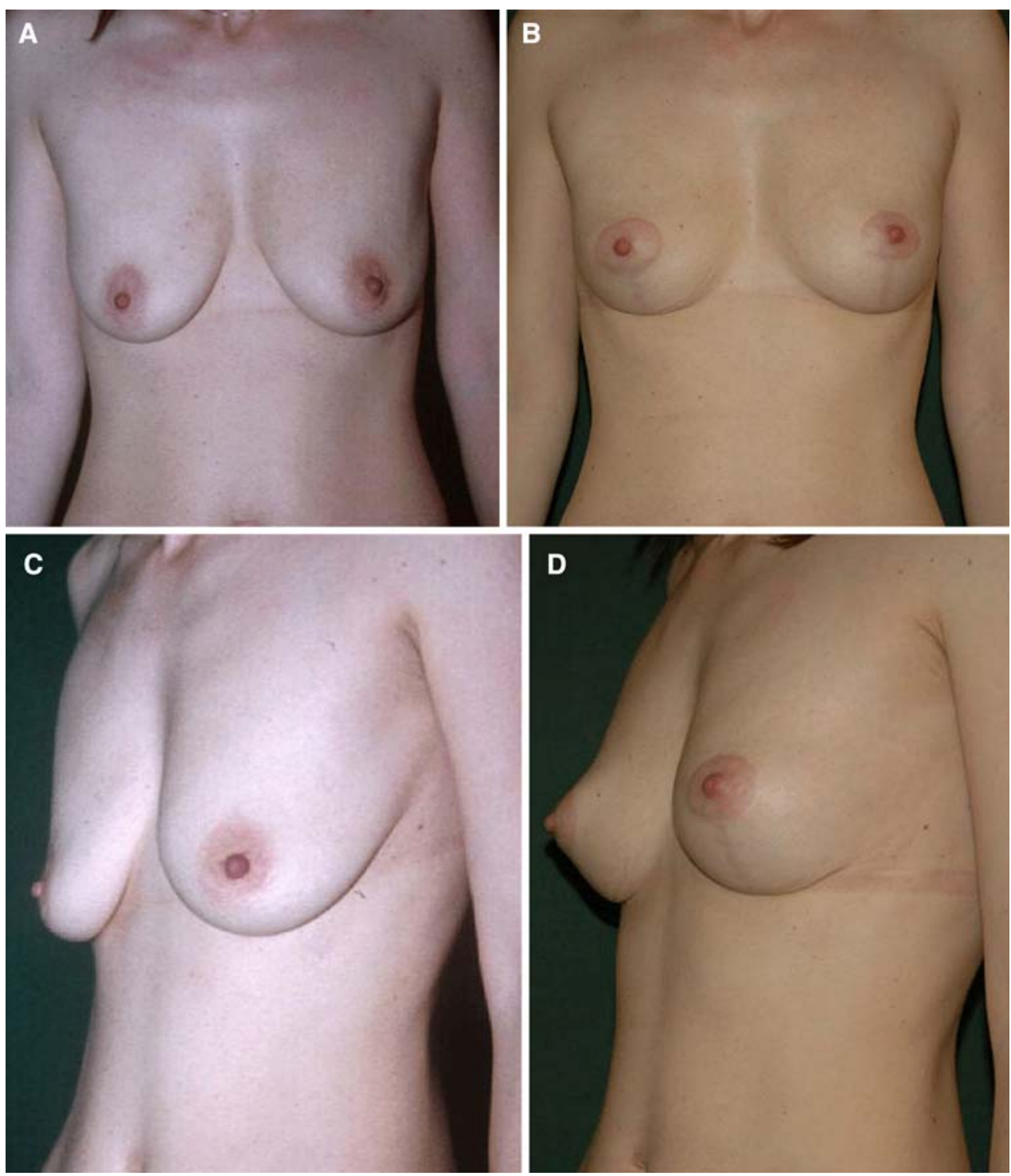

D

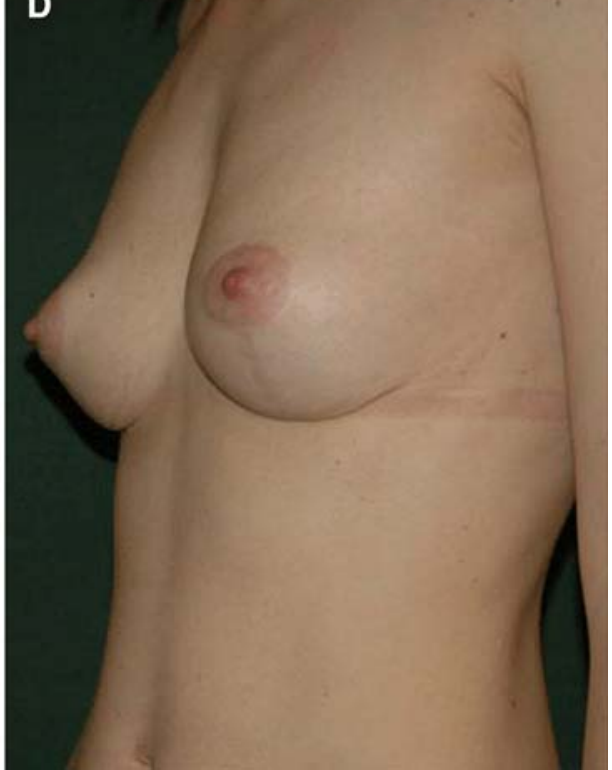

a deficit. This tissue works as a natural prosthesis and provides good vascularization for the lower portion of the breast. The inferior pedicle allows shifting of the pedicle under the central parenchyma of the breast behind the NAC to the area that usually is loose and empty. The technique also has a conization effect from vertical reduction using the method described by Lassus [10], Lejour [11] and Marchac [13]. The inferior pedicle preserves the bottoming out because the flap is attached to the pectoralis major fascia, thereby reducing the weight of the remaining breast. This allows elevation of the inframammary fold and reduction of the base, as confirmed by our results. However, fixation of the flap to the pectoralis major is critical [14-20]. It is imperative that a predictable and strong fixation to the pectoralis major fascia be obtained because the muscle fibers alone are prone to rupture.

To achieve aesthetically pleasant pole fullness, a long volumetric pedicle usually is needed when autoaugmentation mammaplasty is performed. Therefore, the volume of the inferior pedicle depends on the distance between the areola and the inframammary fold. Its upper limit is located $1 \mathrm{~cm}$ below the inferior edge of the areola. The distance between the lateral and medial borders of the breast pillars and the base of the pedicle extending to the inframammary crease defines the width of the flap, which is approximately 6 to $8 \mathrm{~cm}$, with a thickness of $4 \mathrm{~cm}$.

Compared with a superior pedicle flap or a McKissock [9] flap, which is folded on itself, the inferior pedicle has the disadvantage that in cases of a short pedicle, it can not be folded on itself. Therefore, the milk ducts will not recanalize because the deepithelialized dermoglandular surface is in contact with the sub areola area. Compared with the lateral pedicle advocated in some reduction mammaplasty procedures for autoaugmentation, which offers limited recruitment of tissue [12], the inferior pedicle is designed to give a better breast shape, with upper 
fullness and more volume, which is imperative in autoaugmention. Ribeiro's [3, 4] technique, involving rotation of an inferior pedicle flap in the upper pole, provides autoaugmentation mammaplasty improvement of upper breast fullness, as our results confirmed.

To stabilize the shape and the size of the areola, which is mandatory, we use a round block suture as described by Hammond et al. [2]. In combination with the pedicle, this provides a conical shape of the breasts with good projection and gives good long-term results.

We believe that the autoaugmentation mammaplasty procedure is suitable for patients with small ptotic breasts who desire repositioning of their breasts with autogenous tissue, thereby avoiding insertion of another implant. The described technique can be used with standard inverted T-incisions, vertical incisions with short incision components, and pure vertical incisions. Depending of the patient's wishes and the volume of the breast, a bipedicle flap also can be used for re-autoaugmentation in certain cases.

\section{Conclusion}

Autoaugmentation mammaplasty is an alternative for patients with small breasts who desire improvement of their breast shape without the use of an implant. It corrects ptosis while increasing the projection and apparent volume of the breast. The advantage of the technique is that it both minimizes the skin scar and optimizes the shape of the breast due to suture fixation of the pillars of the breast parenchyma.

\section{References}

1. Ramirez OM (2008) The owl technique combined with the inferior pedicle in mastopexy. Aesth Plast Surg 32:16-17
2. Hammond DC, Khuthaila DK, Kim J (2007) The interlocking Gore-Tex suture for control of areolar diameter and shape. Plast Reconstr Surg 119:804-809

3. Ribeiro L, Accorsi A Jr, Buss A, Marcal-Pessoa M (2002) Creation and evolution of 30 years of the inferior pedicle in reduction mammaplasties. Plast Reconstr Surg 110:960-970

4. Ribeiro L (1975) A new technique for reduction mammaplasty. Plast Reconstr Surg 55:330-334

5. Graf R, Biggs TM, Steely RL (2000) Breast shape: A technique for better upper pole fullness. Aesth Plast Surg 24:348-352

6. Graf R, Biggs TM (2002) In search of better shape in mastopexy and reduction mammoplasty. Plast Reconstr Surg 110:309-317

7. Graf R, Biggs TM (2006) Mastopexy with a pectoralis loop. In: Spear S (ed) Surgery of the breast, 2nd edn. Lippioncott Williams \& Wilkins, Philadelphia, pp 1008-10039

8. Ramirez OM (2002) Reduction mammaplasty with the "owl" incision and no undermining. Plast Reconstr Surg 109:512-522

9. McKissock PK (1972) Reduction mammaplasty with a vertical dermal flap. Plast Reconstr Surg 49:245-252

10. Lassus C (1987) Breast reduction: Evolution of a technique-a single vertical scar. Aesth Plast Surg 11:107-112

11. Lejour M (1993) Vertical mammaplasty. Plast Reconstr Surg 92:985-986

12. Hall-Findlay EJ (2002) Pedicles in vertical breast reduction and mastopexy. Clin Plast Surg 29:379-391

13. Marchac D, de Olarte G (1982) Reduction mammaplasty and correction of ptosis with a short inframammary scar. Plast Reconstr Surg 69:45-55

14. Mottura AA (2003) Circumvertical reduction mastoplasty: New considerations. Aesth Plast Surg 27:85-93

15. Loustau HD, Mayer HF, Sarrabayrouse M (2008) The owl technique combined with the inferior pedicle in mastopexy. Aesth Plast Surg 32:11-15

16. Widgerow $\mathrm{AD}$ (2005) Breast reduction with inferior pedicle fascial suspension. Aesth Plast Surg 29:532-537

17. Rohrich RJ, Gosman AA, Brown SA, Reisch J (2006) Mastopexy preferences: a survey of board-certified plastic surgeons. Plast Reconstr Surg 118:1631-1638

18. Pennington DG (2006) Improving the results of inferior pedicle breast reduction using pedicle suspension and plication. Aesth Plast Surg 30:390-394

19. Daniel MJ (1994) Mamoplastia com retahlo de musculo peitoral. Arch Catarinense Med 23(Suppl 1):119

20. de Araujo Cerqueira A (1998) Mammoplasty: breast fixation with dermoglandular mono upper pedicle flap under the pectoralis muscle. Aesth Plast Surg 22:276-283 